\title{
A Bingham-Plastic Model for Fluid Mud Transport Under Waves and Currents*
}

\author{
LIU Chun-rong (刘春嵘) ${ }^{\mathrm{a}, ~}{ }^{1}$, WU Bo (吴 博) ${ }^{\mathrm{a}}$ and HUHE Ao-de (呼和敖德) \\ ${ }^{a}$ School of Civil Engineering and Architecture, Xiamen University of Technology, Xiamen 361024, China \\ ${ }^{\mathrm{b}}$ Institute of Mechanics Chinese Academy of Sciences, Beijing 100190, China
}

(Received 17 August 2012; received revised form 9 May 2013; accepted 12 August 2013)

\begin{abstract}
Simplified equations of fluid mud motion, which is described as Bingham-Plastic model under waves and currents, are presented by order analysis. The simplified equations are non-linear ordinary differential equations which are solved by hybrid numerical-analytical technique. As the computational cost is very low, the effects of wave current parameters and fluid mud properties on the transportation velocity of the fluid mud are studied systematically. It is found that the fluid mud can move toward one direction even if the shear stress acting on the fluid mud bed is much smaller than the fluid mud yield stress under the condition of wave and current coexistence. Experiments of the fluid mud motion under current with fluctuation water surface are carried out. The fluid mud transportation velocity predicted by the presented mathematical model can roughly match that measured in experiments.
\end{abstract}

Key words: motion of fluid mud; fluid mud transport; Bingham-Plastic model; wave-current interaction

\section{Introduction}

Fluid mud is a highly concentrated near-bed suspension of fine sediments. In estuary and coastal areas, fluid mud is often observed (Li et al., 2004; Sun, 2003; Zhao, 1991; Cao, 1987). The motion of fluid mud has great influences on many coastal projects related to navigation channels, harbors, shoreline protections, and water quality control. Understanding the formation, development, disappearance and transport mechanisms of fluid mud is of great significance for coastal engineering and geology.

Since last decades, studies about the fluid mud transport have been reported in many literatures. Bed shear stress (shear stress on the interface of the water and fluid mud) is regarded as one of the important mechanisms that drive fluid mud moving. Chen (1965) carried out an experiment in a water flume. The motion of the fluid mud on the flat bottom is not observed when the bed shear stress is smaller than the critical incipience shear stress. When the bed shear stress is larger than the critical incipience shear stress, the interface of the water and fluid mud becomes unstable and the sediment on the bed is picked up. In the case that bed shear stress is large enough, both suspended and bed sediment transport of the fluid mud occur (Zhao, 1982; Cao, 1992). Many experimental studies on the critical incipient shear stress (Dou, 1999; van Kessel and Kranenburg, 1996; Hong and Ying, 1988; Tang, 1963) show that the critical incipience shear stress of fluid mud is smaller than its yield stress. It

\footnotetext{
* This research was financially supported by the 300000DWT Waterway of Lianyungang Harbor Construction Project, and the National Natural Science Foundation of China (Grant No. 11272116).

1 Corresponding author. E-mail: liucr@tsinghua.edu.cn
} 
implies that bed shear stress cannot drive fluid mud moving if the interface of the water and fluid mud is not destroyed.

Gravity was introduced by some scholars to explain the motion of the fluid mud layer on the slope. Except the experiment of the fluid mud motion on the flat bottom, Chen (1965) also carried out the experiment of the fluid mud motion on the slope. The movement of the whole layer fluid mud on the slope is observed when the interface of the water and fluid mud is stable. Subsequently, van Kessel and Kranenburg (1996), Cao (1992), Balmforth and Craster (1999), and Chowdhury and Testilk (2011) have studied the transport of the fluid mud on the inclined bottom and found that the whole layer fluid mud will slide if the stress induced by gravity exceeds the yield stress of the fluid mud.

There were also some studies about the interaction of waves and fluid mud (Cao, 1987; Mei and Liu, 1987; Zhao and Jiang, 1989). These studies show that waves can induce the fluid mud motion under the condition that no significant interfacial mixing appears. The transportation of the fluid mud due to the nonlinear interaction of the waves and the fluid mud, which is related to the long-term change of bed level along a muddy coast, is also revealed by some researchers (Becker and Bercovici, 2001; $\mathrm{Ng}$ and $\mathrm{Fu}, 2002) . \mathrm{Ng}$ (2004) pointed out that the fluid mud that hardly moves under normal conditions may be mobilized to flow at an extremely high rate when waves are severely high. The wave-induced gravity-forced fluid mud flow was also reported in some literatures (Traykovski et al., 2000; Puig et al., 2003). These studies indicate that fluid mud may prone to move when waves and currents coexist. Unfortunately, the behaviors of fluid mud under waves and currents are not very clear up to now. Zhao et al. (2006) developed a numerical model to study the interactions among waves, current, and mud, and obtained some useful conclusions. However, systematic studies on the effects of parameters of waves and currents on the fluid mud transportation are needed.

In this paper, a simple mathematical model, in which the relation of the stress and strain of the fluid is assumed to satisfy the Bingham-Plastic model, is presented to understand the mechanism of the motion of fluid mud under waves and currents. The studied scenarios are that the fluid mud layer moves on the flat bottom, the interface of the water and fluid mud is stable, and the thickness of the fluid mud is much smaller than the wave length. The equations of fluid mud motion are simplified by the method of order analysis. The simplified equations are nonlinear ordinary differential equations which are solved by hybrid numerical-analytical technique. Since the computational cost of the presented method is very low, a large number of cases can be simulated. According to the simulation of many cases, the effects of parameters of waves and currents on the fluid mud transportation are discussed. Motions of fluid mud under currents with the fluctuating water surface are studied experimentally. The fluid mud transportation velocity measured in experiments is compared with that calculated by the theoretical model.

\section{Mathematical Model}

By referring to Fig. 1, let the horizontal coordinate, $x$, be pointing in the direction of currents flow, the vertical coordinate, $z$, be pointing upward, and the origin located at the fluid mud surface. The top layer is the clear water, and the bottom layer is fluid mud. The water depth and thickness of the 
fluid mud layer are designated as $h$ and $H$, respectively.

Fig. 1. Definition sketch.

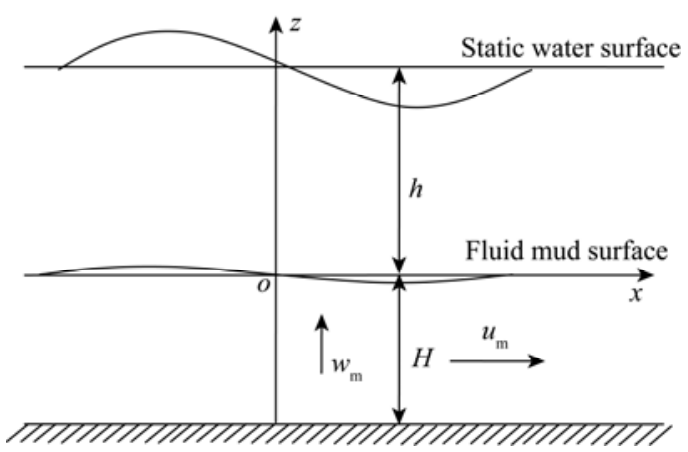

Assuming that there is no interfacial mixing between the fluid mud layer and the clear water, the two-dimensional momentum and continuity equations of fluid mud are expressed as Eqs. (1) and (2), respectively:

$$
\begin{aligned}
& \frac{\partial\left(\rho_{\mathrm{m}} u_{\mathrm{m}}\right)}{\partial t}+u_{\mathrm{m}} \frac{\partial\left(\rho_{\mathrm{m}} u_{\mathrm{m}}\right)}{\partial x}+w_{\mathrm{m}} \frac{\partial\left(\rho_{\mathrm{m}} u_{\mathrm{m}}\right)}{\partial z}=-\frac{\partial p_{\mathrm{m}}}{\partial x}+\frac{\partial \tau_{\mathrm{m}}}{\partial z} \\
& \frac{\partial\left(\rho_{\mathrm{m}} w_{\mathrm{m}}\right)}{\partial t}+u_{m} \frac{\partial\left(\rho_{\mathrm{m}} w_{\mathrm{m}}\right)}{\partial x}+w_{\mathrm{m}} \frac{\partial\left(\rho_{\mathrm{m}} w_{\mathrm{m}}\right)}{\partial z}=-\frac{\partial p_{\mathrm{m}}}{\partial z}-\rho_{\mathrm{m}} g+\frac{\partial \tau_{\mathrm{m}}}{\partial x} \\
& \frac{\partial u_{\mathrm{m}}}{\partial x}+\frac{\partial w_{\mathrm{m}}}{\partial z}=0,
\end{aligned}
$$

where $u_{\mathrm{m}}$ and $w_{\mathrm{m}}$ are the velocities of fluid mud in $x$ and $z$ direction, respectively; $g$, the gravitational acceleration; $\rho_{\mathrm{m}}$, the bulk density of fluid mud; $\tau_{\mathrm{m}}$, the shear stress of the fluid mud; $p_{m}$, the pressure in fluid mud. In order to enclose Eqs. (1) and (2), the constitutive relation of the fluid mud must be given. Abundant data available show that mud rheology is essentially Bingham plastic (van Kessel and Kranenburg, 1996; Mei and Liu, 1987). For Bingham plastic, the following stress and strain relations are satisfied:

$$
\begin{aligned}
& \mu_{\mathrm{m}} \frac{\partial u_{\mathrm{m}}}{\partial z}=0, \quad\left|\tau_{\mathrm{m}}\right|<\tau_{\mathrm{y}} \\
& \mu_{\mathrm{m}} \frac{\partial u_{\mathrm{m}}}{\partial z}=\tau_{\mathrm{m}}-\tau_{\mathrm{y}} \operatorname{sgn} \frac{\partial u_{\mathrm{m}}}{\partial z}, \quad\left|\tau_{\mathrm{m}}\right|>\tau_{y}
\end{aligned}
$$

where $\mu_{m}$ is the Bingham viscosity, and $\tau_{\mathrm{y}}$ is the fluid mud yield stress. For simplicity, linear harmonic waves, whose wave length and period are denoted by $L$ and $T$, respectively, are employed instead of real waves.

For gravity waves, the order of the wave length is generally larger than $1 \mathrm{~m}$. As we investigate the case that no significant interfacial mixing occurs, $\tau_{\mathrm{m}}$ is lower than $\tau_{\mathrm{y}}$. For the fluid mud taken from the Lianyungang harbor, $\tau_{\mathrm{y}}$ is smaller than $10 \mathrm{~Pa}$ when the bulk density of the fluid mud is lower than $1250 \mathrm{~kg} / \mathrm{m}^{3}$. When we study these fluid mud samples, the following relation is satisfied:

$$
\tau_{\mathrm{m}} \ll \rho_{\mathrm{m}} g L .
$$


For most cases, the thickness of the fluid mud layer is much smaller than the wave length. Thus Eq. (1) can be simplified as:

$$
\begin{aligned}
& \frac{\partial u_{\mathrm{m}}}{\partial t}=-\frac{1}{\rho_{\mathrm{m}}} \frac{\partial p_{\mathrm{m}}}{\partial x}+\frac{1}{\rho_{\mathrm{m}}} \frac{\partial \tau_{\mathrm{m}}}{\partial z} ; \\
& \frac{\partial p_{\mathrm{m}}}{\partial z}=-\rho_{\mathrm{m}} g .
\end{aligned}
$$

By integrating the first equation of Eq. (6), the following equation is derived

$$
H \frac{\partial U_{\mathrm{m}}}{\partial t}=-\frac{1}{\rho_{\mathrm{m}}} \int_{-H}^{0} \frac{\partial p_{\mathrm{m}}}{\partial x} \mathrm{~d} z+\frac{1}{\rho_{\mathrm{m}}}\left[\tau_{\mathrm{i}}-\tau_{\mathrm{m}}(-H)\right] ; \quad U_{\mathrm{m}}=\frac{1}{H} \int_{-H}^{0} u_{\mathrm{m}} \mathrm{d} z,
$$

where $\tau_{\mathrm{i}}$ is the shear stress on the interface of the water and fluid mud, and $\tau_{\mathrm{m}}(-H)$ is the shear stress on the bottom of fluid mud layer. When $\tau_{\mathrm{m}}(-H)<\tau_{\mathrm{y}}$, fluid mud cannot move. When $\tau_{\mathrm{m}}(-H)>\tau_{\mathrm{y}}$, two distinct flow zones appear in the fluid mud layer, one is the plug flow zone, and another is the shear flow zone. In the plug flow, the shear stress is smaller than the yield stress, $u_{\mathrm{m}}$ must be uniform in $z$. In the shear flow, the shear stress exceeds the yield stress, and $u_{\mathrm{m}}$ varies in $z$.

The order of the shear flow thickness can be estimated by Mei and Liu (1987):

$$
\delta_{\mathrm{m}}=O\left(\sqrt{\frac{v_{\mathrm{m}}}{\omega}}\right)
$$

where $v_{\mathrm{m}}=\frac{\mu_{\mathrm{m}}}{\rho_{\mathrm{m}}}$, and $\omega$ is the angular frequency of wave.

The order of the pressure gradient induced by waves can be estimated by the following equation

$$
O\left(\frac{\partial p_{\mathrm{m}}}{\partial x}\right) \sim O\left(\frac{\rho g k A_{0}}{\cosh (k h)}\right)
$$

where $k$ is the wave number, and $A_{0}$, the wave amplitude. According to the first equation of Eq. (6) and Eq. (9), the order of $u_{\mathrm{m}}$ is estimated by

$$
O\left(u_{\mathrm{m}}\right) \sim O\left(\frac{g k A_{0}}{\omega \cosh (k h)}\right) \text {. }
$$

By referring to Eqs. (8) and (10), the order of $\frac{\mu_{\mathrm{m}} \frac{\partial u_{\mathrm{m}}}{\partial z}}{\tau_{\mathrm{y}}}$ can be estimated by

$$
O\left(\frac{\mu_{\mathrm{m}} \frac{\partial u_{\mathrm{m}}}{\partial z}}{\tau_{\mathrm{y}}}\right) \sim O\left(\sqrt{\frac{\nu_{\mathrm{m}}}{\omega}} \frac{\rho_{\mathrm{m}} g k A_{0}}{\cosh (k h) \tau_{\mathrm{y}}}\right) .
$$


When we study the small amplitude waves, the condition $O\left(\frac{\mu_{\mathrm{m}} \frac{\partial u_{\mathrm{m}}}{\partial z}}{\tau_{\mathrm{y}}}\right) \ll 1$ can be satisfied. Thus Eq. (7) can be simplified as:

$$
H \frac{\partial U_{\mathrm{m}}}{\partial t}=-\frac{1}{\rho_{\mathrm{m}}} \int_{-H}^{0} \frac{\partial p_{\mathrm{m}}}{\partial x} \mathrm{~d} z+\frac{1}{\rho_{\mathrm{m}}}\left[\tau_{\mathrm{i}}-\tau_{\mathrm{y}} \operatorname{sgn}\left(\frac{\partial u_{\mathrm{m}}}{\partial z}\right)\right] .
$$

Referring to Eqs. (3) and (4), the sign of $\frac{\partial u_{\mathrm{m}}}{\partial z}$ is the same in the whole layer of fluid mud, and $\operatorname{sgn} \frac{\partial u_{\mathrm{m}}}{\partial z}=\operatorname{sgn}\left(U_{\mathrm{m}}\right)$. Eq. (12) is rewritten as:

$$
H \frac{\partial U_{\mathrm{m}}}{\partial t}=-\frac{1}{\rho_{\mathrm{m}}} \int_{-H}^{0} \frac{\partial p_{\mathrm{m}}}{\partial x} \mathrm{~d} z+\frac{1}{\rho_{\mathrm{m}}}\left[\tau_{\mathrm{i}}-\tau_{\mathrm{y}} \operatorname{sgn}\left(U_{\mathrm{m}}\right)\right] .
$$

\section{Calculation Method}

In order to solve Eq. (13), the value of $\frac{\partial p_{\mathrm{m}}}{\partial x}$ and $\tau_{\mathrm{i}}$ must be given. According to the second equation of Eq. (6), we have

$$
p_{\mathrm{m}}=-\rho_{\mathrm{m}} g(z-\xi)+p_{\mathrm{i}},
$$

where $p_{\mathrm{i}}$ is the pressure of fluid mud surface, and $\xi$, the fluctuation amplitude of fluid mud surface. The value of $\frac{\partial p_{\mathrm{m}}}{\partial x}$ is given as:

$$
\frac{\partial p_{\mathrm{m}}}{\partial x}=\rho_{\mathrm{m}} g \frac{\partial \xi}{\partial x}+\frac{\partial p_{\mathrm{i}}}{\partial x}
$$

The dispersion relation of gravity wave gives

$$
\frac{(2 \pi)^{2}}{T^{2}}=g \frac{2 \pi}{L} \tan (k h) .
$$

According to Eq. (16), the order of the wave length can be estimated as:

$$
O(L) \sim O\left(g T^{2}\right) .
$$

In this paper, we study the conditions that $H / L \ll 1$, which is suitable for most cases in estuary and coastal areas. Thus the following relation can be obtained

$$
L^{2} \gg g H T^{2},
$$

where $T$ is the wave period. According to continuity equation, the order of the fluctuation amplitude of the fluid mud surface can be estimated as:

$$
O(\xi) \sim O\left(u_{\mathrm{m}} H T / L\right) .
$$

Considering the order of $u_{\mathrm{m}}$ estimated by Eq. (10) and the relation Eq. (18), we can obtain the following relation: 


$$
\xi \ll A_{0} / \cosh (k h) .
$$

According to Eq. (20), the contribution of $\xi$ to $\frac{\partial p_{\mathrm{m}}}{\partial x}$ can be ignored, and the following expression of $\frac{\partial p_{\mathrm{m}}}{\partial x}$ is obtained:

$$
\frac{\partial p_{\mathrm{m}}}{\partial x}=-\rho g k A_{0} \frac{\cos (\omega t-k x)}{2 \cosh (k h)} .
$$

Substituting Eq. (21) into Eq. (13) gives:

$$
\frac{\partial U_{\mathrm{m}}}{\partial t}=\frac{\rho}{\rho_{\mathrm{m}}} \frac{g k A_{0}}{2 \cosh (k h)} \cos (\omega t-k x)+\frac{1}{\rho_{\mathrm{m}} H}\left[\tau_{\mathrm{i}}-\tau_{\mathrm{y}} \operatorname{sgn}\left(U_{\mathrm{m}}\right)\right] .
$$

Both currents and waves can contribute to $\tau_{\mathrm{i}}$. In order to simplify the problem, we ignored the contribution of waves to $\tau_{\mathrm{i}}$. This assumption is reasonable since waves can drive fluid mud moving even at a very small bed shear stress. If the current velocity is a constant, the value of shear stress $\tau_{\mathrm{i}}$ can be regarded as a constant. The dimensionless form of Eq. (22) can be written as:

$$
\partial U_{\mathrm{m}}^{*} / \partial t^{*}=B \cos \left(t^{*}-x^{*}\right)+C\left[\tau_{\mathrm{i}}^{*}-\operatorname{sgn}\left(U_{\mathrm{m}}^{*}\right)\right],
$$

where $U_{\mathrm{m}}^{*}=\frac{2 U_{\mathrm{m}} \cosh (k h)}{A_{0} \omega}, t^{*}=\omega t, x^{*}=k x, \tau_{\mathrm{i}}^{*}=\frac{\tau_{\mathrm{i}}}{\tau_{y}}, B=\frac{\rho}{\rho_{\mathrm{m}}} \frac{g k}{\omega^{2}}$, and $C=\frac{2 \tau_{\mathrm{y}} \cosh (k h)}{\rho_{\mathrm{m}} H A_{0} \omega^{2}}$. Let $\sigma=t^{*}-x^{*}$, Eq. (23) can be expressed as:

$$
\mathrm{d} U_{\mathrm{m}}^{*} / \mathrm{d} \sigma=B \cos \sigma+C\left[\tau_{\mathrm{i}}^{*}-\operatorname{sgn}\left(U_{\mathrm{m}}^{*}\right)\right] .
$$

By integrating Eq. (24), the non-dimensional velocity of the fluid mud is given by

$$
U_{\mathrm{m}}^{*}=B\left(\sin \sigma-\sin \sigma_{1}\right)+C\left[\tau_{\mathrm{i}}^{*}-\operatorname{sgn}\left(U_{\mathrm{m}}^{*}\right)\right]\left(\sigma-\sigma_{1}\right),
$$

where $\sigma_{1}$ is the value of $\sigma$ as fluid mud begins to move. It is must be noted that Eq. (25) is only valid when the shear stress on the bottom of fluid mud layer is larger than the fluid mud yield stress (i.e. $\tau_{\mathrm{m}}(-H)>\tau_{\mathrm{y}}$ ). A hybrid numerical-analytical technique is employed to calculate the velocity of fluid mud. As Eq. (25) is used to calculate $U_{\mathrm{m}}^{N}$ (velocity of the fluid mud at time step $N$ ), $U_{\mathrm{m}}^{N-1}$ (velocity of fluid mud at time step $N-1$ ) is known. If $U_{\mathrm{m}}^{N-1} \neq 0, U_{\mathrm{m}}^{N}$ is calculated by Eq. (25) with $\operatorname{sgn}\left(U_{\mathrm{m}}^{*}\right)=\operatorname{sgn}\left(U_{\mathrm{m}}^{N-1}\right)$. Otherwise the value of $F=B \cos \sigma+C \tau_{\mathrm{i}}^{*}$ must be calculated. Under the conditions that $U_{\mathrm{m}}^{N-1}=0$ and $|F|>C, U_{\mathrm{m}}^{N}$ is calculated by Eq. (25) with $\operatorname{sgn}(F)=\operatorname{sgn}\left(U_{\mathrm{m}}^{*}\right)$. Under the conditions that $U_{\mathrm{m}}^{N-1}=0$ and $|F| \leq C, U_{\mathrm{m}}^{N}$ is set to be zero. By this way, the time history of $U_{\mathrm{m}}^{*}$ can be obtained.

\section{Numerical Results and Discussions}

\subsection{Time History of Fluid Mud Velocity}

For the fluid mud which is still initially, its movement cannot occur under the condition of 
$B+C\left(\tau_{\mathrm{i}}^{*}-1\right)<0$. In the case that no waves exist, the condition of $B+C\left(\tau_{\mathrm{i}}^{*}-1\right)<0$ becomes $\tau_{\mathrm{i}}^{*}<1$, which means that the motion of fluid mud layer is impossible if the shear stress on the interface of water and fluid mud is smaller than the yield stress of fluid mud. Under the action of waves, the motion of fluid mud layer becomes possible even if the shear stress on the interface of water and fluid mud approaches zero. Mei and Liu (1987) studied the motion of fluid mud under the condition that only waves exist. The study shows that intermittent and continuous flow occurs subsequently as the wave amplitude increases.

Under the interaction of waves and currents, intermittent and continuous flows of fluid mud are also revealed by the presented model. The time history of the fluid mud velocity under waves and currents is obtained by solving Eq. (25) numerically. The time history of fluid mud velocity under the condition of intermittent flows is shown in Fig. 2a, and that under the condition of continuous flows is shown in Fig. 2b. The intermittent and continuous flows under waves and currents presented in this paper are similar as those under waves presented by Mei and Liu (1987). However, the average velocity of fluid mud during one wave period is not zero in Fig. 2. When fluid mud begins to move, the average velocity of the fluid mud approaches a constant, which is defined as the transportation velocity of fluid mud, after one (for intermittent flows) or several (for continuous flows) wave periods. Since the shear stress on the interface of water and fluid mud is much smaller than the yield stress of fluid mud for the cases in Fig. 2, it can be deduced that weak currents can induce the transportation of fluid mud with the help of waves.

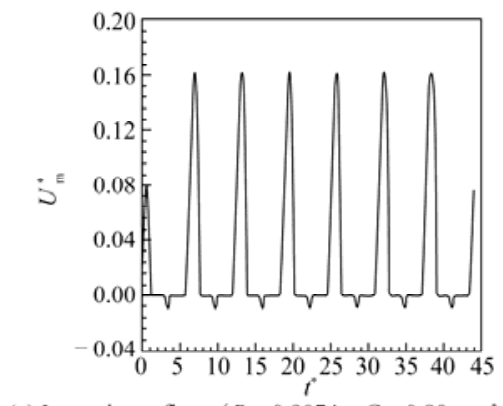

(a) Intermittent flow $\left(B=0.9074, C=0.80, \tau_{\mathrm{i}}^{*}=0.20\right)$

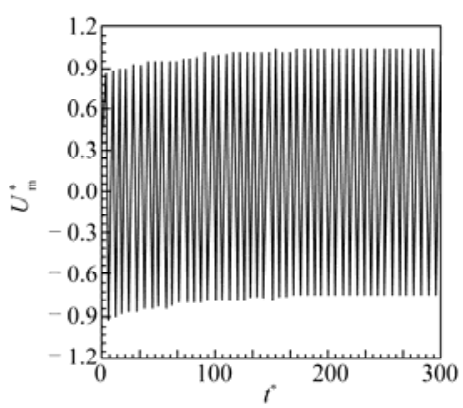

(b) Continuous flow $\left(B=0.9074, C=0.0224, \tau_{\mathrm{i}}^{*}=0.10\right)$

Fig. 2. Time history of the fluid mud velocity under waves and currents.

\subsection{Transport Velocity of Fluid Mud}

Under waves and currents, fluid mud transport velocity $U_{\mathrm{t}}$ depends on the wave amplitude $A_{0}$, wave-length $L$, shear stress on the interface of the water and fluid mud $\tau_{\mathrm{i}}$, yield stress of fluid mud $\tau_{\mathrm{y}}$, water depth $h$, thickness of fluid mud layer $H$, bulk density of fluid mud $\rho_{\mathrm{m}}$, and density of water $\rho$.

$$
U_{\mathrm{t}}=f\left(A_{0}, L, \rho, \tau_{\mathrm{i}}, h, H, \rho_{\mathrm{m}}, \tau_{\mathrm{y}}\right) .
$$

By choosing $\rho_{\mathrm{m}}, h$, and $\tau_{\mathrm{y}}$ as characteristic variables, Eq. (26) can be written as the following dimensionless form by Buckingham $\pi$ theorem: 


$$
U_{\mathrm{t}} / \sqrt{\tau_{\mathrm{y}} / \rho_{\mathrm{m}}}=f\left(\frac{A_{0}}{h}, \frac{L}{h}, \frac{\tau_{\mathrm{i}}}{\tau_{\mathrm{y}}}, \frac{H}{h}, \frac{\rho_{\mathrm{m}}}{\rho}\right) .
$$

In order to study the variation of the transportation velocity of fluid mud with the parameters of current, wave, fluid mud bulk density and fluid mud layer thickness, the time history of $U_{\mathrm{m}}^{*}$ under different values of $\tau_{\mathrm{i}} / \tau_{\mathrm{y}}, A_{0} / h, L / h, H / h$ and $\rho_{\mathrm{m}} / \rho$ is obtained by solving Eq. (25) numerically. According to the value of $U_{\mathrm{m}}^{*}$, the instantaneous velocities of fluid mud can be calculated. By averaging the instantaneous velocity after several wave periods, the transportation velocity of fluid mud can be given. Based on the numerical simulation results, the variations of dimensionless transport velocity of fluid mud with $\tau_{\mathrm{i}} / \tau_{\mathrm{y}}$ under the different values of $A_{0} / h, L / h$, $H / h$ and $\rho_{\mathrm{m}} / \rho$ are obtained and shown in Fig. 3. It is found that current is necessary for fluid mud transportation. In the case of no current existence, which corresponds to $\tau_{\mathrm{i}}=0$, no fluid mud transportation occurs. Under the condition that only currents exist, the motion of the whole fluid mud layer on the flat bottom is impossible if the bed shear stress is smaller than the yield shear stress of the fluid mud. As currents and waves coexist, the motion of the whole fluid mud layer on the flat bottom becomes possible even if $\tau_{\mathrm{i}} / \tau_{\mathrm{y}} \ll 1$ because the pressure gradient induced by waves can overcome the yield shear stress of the fluid mud. The transportation velocity of fluid mud increases with the increase of the current velocity and wave amplitude (see Fig. 3a).

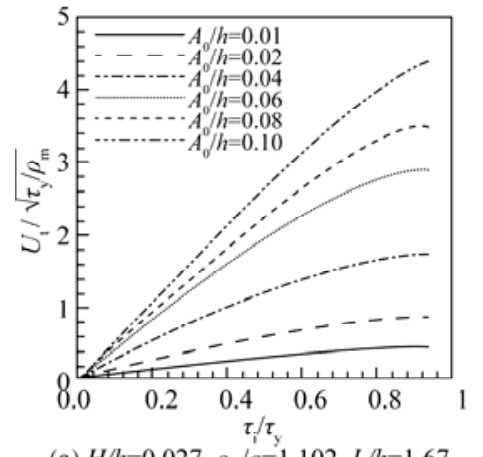

(a) $H / h=0.027, \rho_{\mathrm{m}} / \rho=1.102, L / h=1.67$

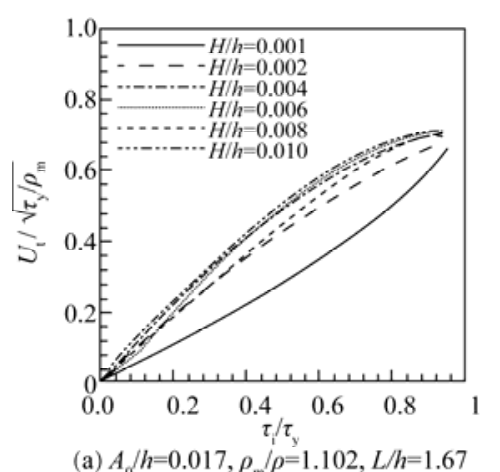

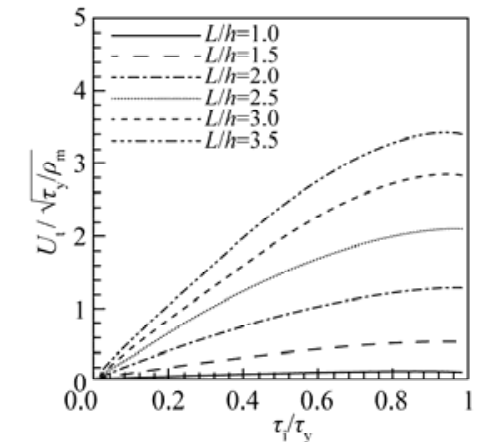

(b) $A_{0} / h=0.017, H / h=0.027, \rho_{\mathrm{m}} / \rho=1.102$

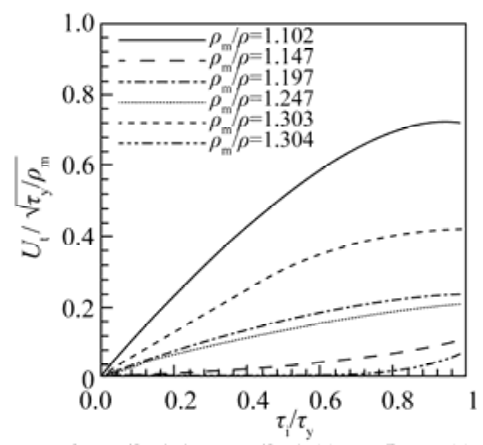

(b) $A_{0} / h=0.017, H / h=0.027, L / h=1.102$

Fig. 3. Variation of the fluid mud velocity with wave-current parameters. 
The effects of the wave length, thickness of the fluid mud layer and the bulk density of fluid mud on the transportation velocity of fluid mud are discussed in the following section. According to the linear wave theory, the effect of gravity wave decays exponentially with the ratio of the water depth to the wave length. For the same wave amplitude, longer waves can induce larger pressure gradient on the interface of water and fluid mud than shorter waves do. When other parameters are the same, the transport velocity of fluid mud under longer waves is higher than that under shorter waves (see in Fig. 3b). The thickness of the fluid mud layer can also affect the transportation velocity of fluid mud. It is seen from Fig. $3 \mathrm{c}$ that larger thickness of the fluid mud layer is beneficial for the transport of the fluid mud. The bulk density of fluid mud has a significant effect on the fluid mud transportation velocity. It is seen from Fig. $3 \mathrm{~d}$ that the fluid mud transportation velocity decreases largely as $\rho_{\mathrm{m}} / \rho$ increases.

\section{Experimental Verification}

Experiments were carried out in a laboratory water flume of $60 \mathrm{~m}$ long, $0.5 \mathrm{~m}$ wide and $0.7 \mathrm{~m}$ high. A fluid mud container of $12 \mathrm{~m}$ long, $0.5 \mathrm{~m}$ wide and $0.2 \mathrm{~m}$ deep was installed in the middle of the flume (see Fig. 4). Natural mud samples taken from Lianyungang harbor were used in experiments. Mud samples of three bulk densities $\left(1155 \mathrm{~kg} / \mathrm{m}^{3}, 1208 \mathrm{~kg} / \mathrm{m}^{3}, 1260 \mathrm{~kg} / \mathrm{m}^{3}\right)$ were prepared in a large container by mixing the original mud samples and then put into the fluid mud container respectively. A hydrometric propeller was installed at the upstream fluid mud container to monitor the velocity of the current. An obstacle at the inlet of the flume was employed to generate the fluctuation of the water surface. As the obstacle was removed, the fluctuation of the water surface can be controlled to be very small.

In order to obtain the shear stress on the interface of the water and fluid mud, the instantaneous flow velocity field in the vertical plane was measured by the technique of PIV. The shear stress on the interface of the water and fluid mud can be calculated based on the velocity profile near the interface of the water and fluid mud, which was obtained by the measurement results of PIV. The time history of the water surface elevation was recorded by a laser distance sensor. The wave spectrum was obtained by performing the fast Fourier transform (FFT) on the time history of the water surface elevation. By matching the obtained wave spectrum with the JONSWAP spectrum, the significant wave height and the peak period can be obtained. The rheological properties of the fluid mud were measured by the HAAKE-RS6000 rotational rheometer.

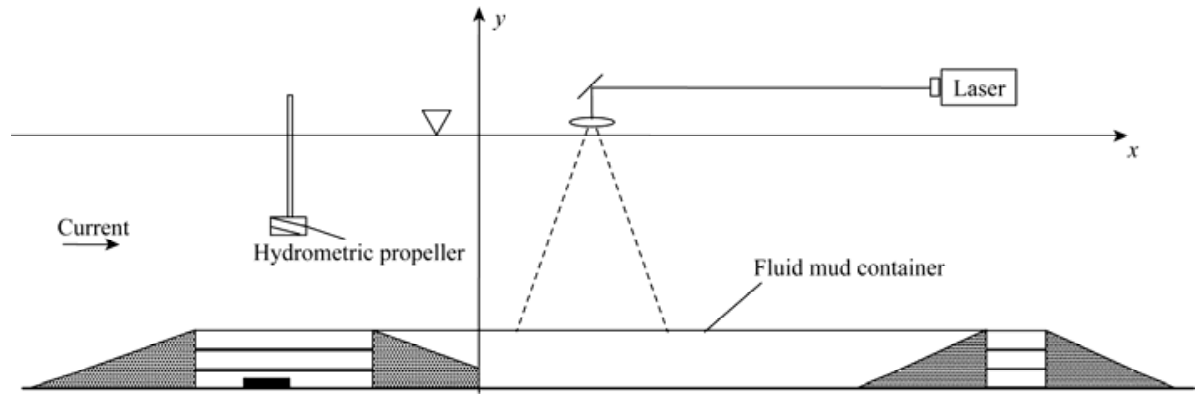

Fig. 4. Sketch of the experiment setup. 
The measurement of the fluid mud velocity is difficult. Up to now, there are few methods have been reported. In the present study, a sheet of fluid mud in the cross section of the water flume was dyed by red color (see in Fig. 5). The positions of the dyed fluid mud sheet on the surface of the fluid mud layer were recorded by the camera. According to the displacement of dyed fluid mud sheet for a period of time, the velocity of the fluid mud on the surface can be calculated.

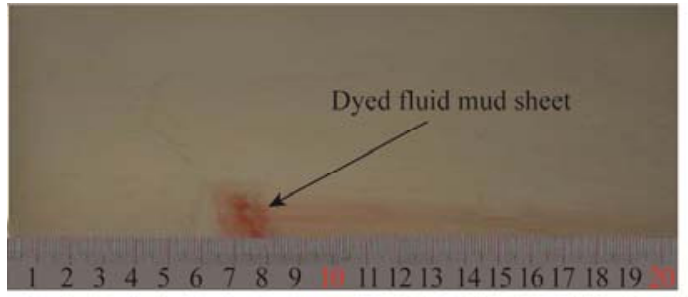

time: $15: 47$

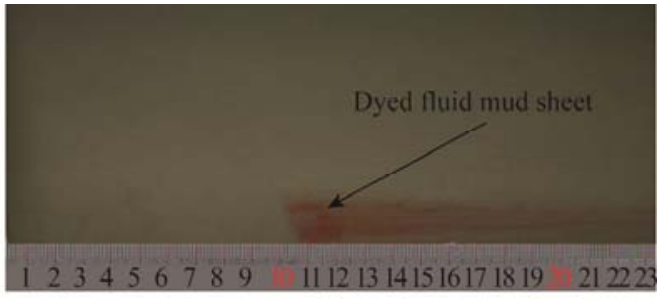

time: $16: 01$

Fig. 5. Dyed fluid mud sheet at different times.

In order to verify the theoretical analysis, the experimental results are presented. Owing to the difficulty of the experiments, only eight cases are tested. The mean velocity of current $U_{\mathrm{c}}$, water depth $h$, the significant wave height $H_{\mathrm{s}}$, the peak period of the water surface fluctuation $T_{\mathrm{p}}$, the bulk density of the fluid mud $\rho_{\mathrm{m}}$ are measured and listed in Table 1 . The thickness of the fluid mud layer $H$ for these eight cases is the same of $12 \mathrm{~cm}$. In the experiments of rheology, the relation of shear rate to the shear stress can be obtained. For the fluid mud samples used in our experiments, the curves of the shear rate versus the shear stress show that they can be described by the Dual-Bingham plastic model proposed by Huhe and Huang (1994) and Huang and Huhe (2009). Two values of the yield stress can be obtained for Dual-Bingham model. One is calculated by the data in low shear rate regime, which is denoted as $\tau_{\mathrm{yl}}$; another is calculated by the data in high shear rate regime, which is denoted as $\tau_{\mathrm{y} 2}$. The values of $\tau_{\mathrm{y} 1}$ and $\tau_{\mathrm{y} 2}$ for the fluid mud with different bulk densities are also listed in Table 1.

Table 1 Parameters of the test programs

\begin{tabular}{|c|c|c|c|c|c|c|c|}
\hline No. & $\rho_{\mathrm{m}} \quad\left(\mathrm{kg} / \mathrm{m}^{3}\right)$ & $U_{\mathrm{c}}(\mathrm{cm} / \mathrm{s})$ & $h(\mathrm{~cm})$ & $\tau_{\mathrm{y} 1}(\mathrm{~Pa})$ & $\tau_{\mathrm{y} 2}(\mathrm{~Pa})$ & $H_{\mathrm{s}}(\mathrm{cm})$ & $T_{\mathrm{p}}(\mathrm{s})$ \\
\hline 1 & 1260 & 28.1 & 35 & 1.476 & 6.68 & 1.02 & 3.31 \\
\hline 2 & 1208 & 18.7 & 35 & 1.175 & 2.57 & 0.00 & - \\
\hline 3 & 1208 & 18.7 & 35 & 1.175 & 2.57 & 0.63 & 4.58 \\
\hline 4 & 1208 & 21.7 & 35 & 1.175 & 2.57 & 0.95 & 4.00 \\
\hline 5 & 1155 & 8.70 & 35 & 0.400 & 0.90 & 0.00 & - \\
\hline 6 & 1155 & 8.70 & 35 & 0.400 & 0.90 & 0.35 & 5.56 \\
\hline 7 & 1155 & 14.0 & 35 & 0.400 & 0.90 & 0.50 & 4.91 \\
\hline 8 & 1155 & 15.4 & 35 & 0.400 & 0.90 & 0.52 & 4.83 \\
\hline
\end{tabular}

In order to compare the experimental results with theoretical one, the bed shear stress for the experimental cases must be given. However directly measuring the bed shear stress is difficult. In this study, the flow velocity fields measured by the technique of PIV were used to calculate the bed shear stress. Fig. 6 shows that the velocity profile near the interface of the water and fluid mud measured by PIV obeys the logarithm law. Thus the bed shear stress can be calculated based on the PIV measuring data. The transportation velocities of the fluid mud for the cases listed in Table 1 are obtained by the theoretical model presented in Section 1. The theoretical results are compared with the experimental one (see Table 2). It is noted that the significant wave height and the peak period measured in 
experiment are taken as the wave height and the period of the harmonic wave in theoretical analysis. In theory, the shear stress of fluid mud are chosen as $\tau_{\mathrm{y} 1}$ and $\tau_{\mathrm{y} 2}$ to calculate the fluid mud transportation velocity respectively. If $\tau_{\mathrm{y} 2}$ is chosen as the yield stress of fluid mud, the transportation velocity predicted by theory and the surface velocity of the fluid mud layer measured experimentally have the same order.

Fig. 6. Velocity profile near the interface of the water and fluid mud measured by PIV obeys the logarithm law.

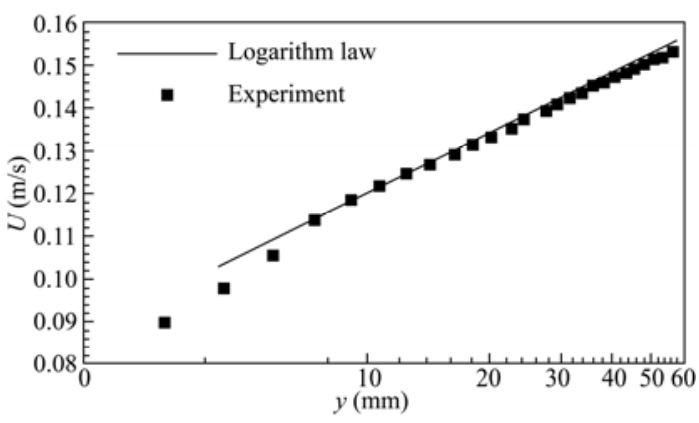

Table 2

Fluid mud transportation velocity obtained by theory and experiments

\begin{tabular}{|c|c|c|c|c|c|c|c|c|c|c|}
\hline \multicolumn{3}{|c|}{ No. } & 1 & 2 & 3 & 4 & 5 & 6 & 7 & 8 \\
\hline \multicolumn{3}{|c|}{$\tau_{\mathrm{i}} \quad(\mathrm{Pa})$} & 0.632 & 0.421 & 0.421 & 0.488 & 0.196 & 0.196 & 0.315 & 0.347 \\
\hline \multirow{3}{*}{$\begin{array}{c}\text { Fluid mud } \\
\text { transport } \\
\text { velocity } \\
(\mathrm{mm} / \mathrm{s})\end{array}$} & \multicolumn{2}{|c|}{ Experiments } & 0.050 & 0.000 & 0.033 & 0.023 & 0.000 & 0.040 & 0.083 & 0.120 \\
\hline & \multirow{2}{*}{ theory } & $\tau_{\mathrm{y}}=\tau_{\mathrm{y} 1}$ & 2.890 & 0.000 & 1.200 & 1.160 & 0.000 & 0.120 & 0.830 & 1.110 \\
\hline & & $\tau_{\mathrm{y}}=\tau_{\mathrm{y} 2}$ & 0.034 & 0.000 & 0.020 & 0.018 & 0.000 & 0.000 & 0.140 & 0.190 \\
\hline
\end{tabular}

\section{Conclusions}

A simplified mathematical model of the fluid mud motion under wave-current is presented and the experiments of fluid mud motion under the currents with fluctuation water surface are carried out. The following conclusions are obtained:

(1) The transportation of the fluid mud can occur even if the bed shear stress is much smaller than the yield stress of fluid mud with the help of waves.

(2) The fluid mud transportation velocity increases with the wave amplitude and wave-length when other parameters are fixed, and larger thickness of the fluid mud layer is beneficial for the transportation of the fluid mud.

(3) The fluid mud transportation velocities predicted by the presented mathematical model have the same order with that measured in experiments.

Acknowledgments - The authors would like to appreciate Prof. Daichin and Mr. WANG Daifeng for their sincere help in experiments.

\section{References}

Balmforth, N. J. and Craster, R. V., 1999. A consistent thin-layer theory for Bingham plastics, Journal of Non-Newtonian Fluid Mechanics, 84(1): 65-81.

Becker, J. M. and Bercovici, D., 2001. Pattern formation on the interface of a two-layer fluid: Bi-viscous lower layer, Wave Motion, 34(4): 431-452. 
Cao, Z. D., 1987. Characteristics of fluid mud motion under waves, Journal of Waterway and Harbor, 8(2): 8-14. (in Chinese)

Cao, Z. D., 1992. Research on fluid mud characteristics, Journal of Waterway and Harbor, 13(1): 34-40. (in Chinese)

Chen, Q., 1965. A study on fluid mud flow under the action of gravity and effect of flowing water and interfacial stability, Journal of Tianjin University, 21(4): 31-52. (in Chinese)

Chowdhury, M. R. and Testilk, F. Y., 2011. Laboratory testing of mathematical models for high-concentration fluid mud turbidity currents, Ocean Eng., 38(1): 256-270.

Dou, G. R., 1999. Incipient motion of coarse and fine sediment, Journal of Sediment Research, (6): 1-13. (in Chinese)

Hong, R. J. and Ying, Y. L., 1988. Research on fluid mud staring velocity under current, Journal of Hydraulic Engineering, 19(8): 49-55. (in Chinese)

Huang, Z. H. and Huhe, Aode, 2009. A laboratory study of rheological properties of mudflows in Hangzhou Bay, China, International Journal of Sediment Research, 24(4): 410-424.

Huhe, Aode and Huang, Z. H., 1994. Experimental study of rheology of Hangzhou Bay mud, International Report IMCAS STR-94021, Institute of Mechanics, Chinese Academy of Sciences. (in Chinese)

Li, J. F., Wan, X. N., He, Q., Ying, M., Shi, L. Q. and Hutchinson, S. M., 2004. In-situ observation of fluid mud in the north passage of Yangtze Estuary, China, China Ocean Eng., 18(1): 149-156.

Mei, C. C. and Liu, K. F., 1987. A Bingham-plastic model for a muddy seabed under long waves, J. Geophys. Res., 92(13): 14581-14594.

$\mathrm{Ng}$, C. O., 2004. Mass transport in a layer of power-law fluid forced by periodic surface pressure, Wave Motion, 39(3): 241-259.

$\mathrm{Ng}, \mathrm{C}$. O. and Fu, S. C., 2002. On the propagation of a two-dimensional viscous density current under surface waves, Physics of fluid, 14(3): 970-984.

Puig, P., Ogston, A. S., Mullenbach, B. L., Nittrouer, C. A. and Sternberg, R. W., 2003. Shelf-to-canyon sediment-transport processes on the Eel continental margin (northern California), Marine Geology, 193(1-2): 129-149.

Sun, L. C., 2003. Research on hydrological and siltation problems of Tianjin port, The Ocean Eng., 21(1): $78-86$. (in Chinese)

Tang, C. B., 1963. Research on sediment incipient motion, Journal of Hydraulic Engineering, 17(2): 1-12. (in Chinese)

Traykovski, P., Geyer, W. R., Irish, J. D. and Lynch, J. F., 2000. The role of wave-induced density-driven fluid mud flows for cross-shelf transport on the Eel River continental shelf, Continental Shelf Research, 20(16): 2113-2140.

van Kessel, T. and Kranenburg, C., 1996. Gravity current of fluid mud on sloping bed, Journal of Hydraulic Engineering, 122(12): 710-717.

Zhao, Z. D., 1982. The fluid mud transport under wave, Marine Science Bulletin, 11(6): 65-74. (in Chinese)

Zhao, Z. D., 1991. Review and prospects on the interaction between waves and mud bottom, The Ocean Eng., 9(2): 33-40. (in Chinese)

Zhao, Z. D. and Jiang, L., 1989. Study on the interaction between waves and mud bottom, China Ocean Eng., 3(3): 321-328.

Zhao, Z. D., Lian, J. J. and Shi, J. Z., 2006. Interaction among waves, current, and mud: Numerical and laboratory studies, Advances in Water Resources, 29(11): 1731-1744. 